\section{VAC.07 - Montagem de controles internos para ensaios de PRNT: Uma necessidade e um grande desafio}

Sheila Maria Barbosa de Lima ${ }^{1}$; Emily Hime Miranda ${ }^{1}$; Marisol Simões ${ }^{1}$; Renata Carvalho Pereira ${ }^{1}$; Caio Bidueira Denani ${ }^{1 *}$; Nathalia dos Santos Alves ${ }^{1}$; Ingrid Siciliano Horbach ${ }^{1}$; Ygara da Silva Mendes ${ }^{1}$; Felipe Soares Figueiredo ${ }^{1}$; Waleska Dias Schwarcz ${ }^{1}$.

\section{Fiocruz/Bio-Manguinhos.}

\section{Introdução:}

O teste de neutralização por redução de placas de lise (PRNT) é considerado o padrão-ouro para a detecção e quantificação dos anticorpos neutralizantes para a avaliação da resposta imune protetora após a vacinação. Para a realização do teste, é necessária a utilização de soros-padrão internacionais ou outros soros-referência como controles internos. Porém, fatores como logística de compra e altos custos são limitantes para a aquisição e uso contínuos dos soros-padrão internacionais. Neste contexto, uma produção interna de soros controle mostra-se como uma alternativa sustentável, dando autonomia ao Laboratório de Tecnologia Virológica (Bio-Manguinhos/ Fiocruz) e maior confiabilidade aos resultados gerados.

\section{Objetivo:}

Avaliar o perfil sorológico das amostras de voluntários para a criação racional de controles internos (positivos e negativos) para utilização em ensaio de PRNT de Dengue (DENV), Febre Amarela (YFV) e Caxumba (MV), definir faixas dos controles para aceitação do teste e acompanhar as flutuações dos títulos dos controles.

\section{Metodologia:}

Trezentas amostras previamente analisadas por PRNT50 para YFV, para os quatro sorotipos de DENV e para MV foram classificadas conforme a distribuição dos títulos. Em seguida, uma análise criteriosa foi realizada para selecionar as amostras utilizadas na composição dos controles internos. Para estabelecer a faixa de aceitação foram realizadas 30 análises para cada controle.

\section{Resultado:}

Aproximadamente $60 \%$ das amostras foram negativas para presença de anticorpo de YFV e o critério de escolha para produzir os controles foi selecionar soros negativos para presença de anticorpos para dengue. Sete e oito soros foram selecionados para compor os controles negativo e positivo, respectivamente. Cerca de $21 \%$ das amostras foram negativas para MV. Dentre os soros positivos, treze foram selecionados para a montagem do controle baixo e sete para o médio, e apenas um para o alto. Posteriormente, foi estabelecida uma faixa de aceitação para os títulos dos controles. Em relação à Dengue, aproximadamente $20 \%$ das amostras mostraram-se negativas para os quatro sorotipos e suas frequências foram calculadas. As amostras positivas mostraram uma boa dispersão por toda a faixa de títulos e foram classificadas como positivas baixas, médias e altas. A partir da análise dos dados obteve-se controles de Dengue que atendam às demandas durante cinco anos.

\section{Conclusão:}

Os controles produzidos para YFV e MV foram inseridos na rotina dos testes de PRNT e a distribuição dos títulos encontra-se dentro da faixa de aceitação pré-estabelecida. O desenho racional de controles para Dengue encontra-se em fase final de execução. A seleção de controles internos é um processo laborioso, pois envolve etapas que vão desde a autorização do Comitê de Ética em Pesquisa para captação de soros até a análise do perfil sorológico. A montagem dos controles internos mostra-se relevante para monitorar a estabilidade do teste ao longo do tempo e aumentar a confiabilidade dos resultados gerados.

\section{Palavras-chave: PRNT; controle interno; perfil sorológico}

